\title{
Pemodelan Data Kemiskinan di Provinsi Jawa Barat Menggunakan Regresi Spasial Data Panel
}

\author{
Nabilah Ninda Nur Azizah ${ }^{1, \text { a) }}$, Siti Rohmah Rohimah ${ }^{1, b)}$, Bagus Sumargo, c) \\ ${ }^{1}$ Program Studi Statistika, Fakultas Matematika dan Ilmu Pengetahuan Alam, Universitas Negeri Jakarta, \\ Jl. Rawamangun Muka, Kota Jakarta Timur, DKI Jakarta, 13220. \\ Email: ${ }^{a)}$ nabilahazzh@gmail.com, b) sitirohmah@unj.ac.id, ${ }^{c}$ bagussumargo@unj.ac.id
}

\begin{abstract}
The percentage of poverty in West Java Province is still quite high and is still being the focus of government attention. It is important to know the factors that influence poverty in order that the government can make the right policy to reduce poverty. Therefore, in this research, an analysis is conducted to determine the factors that influence the rate of poverty in West Java Province. The analysis in this research using panel data spatial regression method because it is suspected that poverty data in West Java Province has a spatial effect, and the unit of observations are observed more than once. The model formed from this analysis is Fixed Effect Spatial Error Model because the spatial interaction formed on poverty data in West Java Province is real in error. This model also managed to be the best model compared to other models based on the criteria for the largest $R$-square value. Analysis of poverty data in West Java Province using panel data spatial regression method shows that life expectancy, adjusted per capita expenditure, and the average length of schooling have a significant effect on the percentage of poor people in West Java Province.
\end{abstract}

Keywords: poverty, panel data spatial regression, fixed effect spatial error model

\begin{abstract}
Abstrak
Persentase kemiskinan di Provinsi Jawa Barat masih tergolong cukup tinggi dan masih menjadi fokus perhatian pemerintah. Faktor-faktor yang memengaruhi kemiskinan penting untuk diketahui agar pemerintah mampu membuat suatu kebijakan yang tepat untuk menekan angka kemiskinan. Oleh karena itu, pada penelitian ini, dilakukan suatu analisis untuk mengetahui faktor-faktor yang memengaruhi tingkat kemiskinan di Provinsi Jawa Barat. Analisis pada penelitian ini menggunakan metode regresi spasial data panel karena diduga pada data kemiskinan di Provinsi Jawa Barat terdapat efek spasial dan unit amatan diamati pada jangka waktu tertentu. Model yang terbentuk dari analisis ini adalah Fixed Effect Spatial Error Model karena interaksi spasial yang terbentuk pada data kemiskinan di Provinsi Jawa Barat nyata pada error. Model ini juga berhasil menjadi model terbaik dibandingkan model lainnya berdasarkan kriteria nilai $R$-square terbesar. Analisis data kemiskinan di Provinsi Jawa Barat menggunakan metode regresi spasial data panel memperoleh hasil bahwa usia harapan hidup, pengeluaran per kapita disesuaikan, dan rata-rata lama sekolah berpengaruh secara signifikan terhadap persentase penduduk miskin di Provinsi Jawa Barat.
\end{abstract}

Kata-kata kunci: kemiskinan, regresi spasial data panel, fixed effect spatial error model 


\section{PENDAHULUAN}

Permasalahan kemiskinan di Indonesia menjadi isu sosial penting yang menjadi fokus perhatian pemerintah sehingga pemerintah berupaya membuat suatu kebijakan untuk mengatasinya, walaupun pada kenyaaannya upaya tersebut belum memberikan hasil yang optimal. Hal ini terbukti dengan persentase penduduk miskin di Indonesia yang masih tergolong cukup tinggi. Persentase penduduk miskin yang cukup tinggi di tingkat nasional didukung oleh persentase penduduk miskin di tingkat provinsi. Provinsi dengan persentase penduduk miskin yang cukup tinggi di Indonesia salah satunya adalah Provinsi Jawa Barat. Provinsi Jawa Barat menempati peringkat ke-3 di pulau Jawa dengan nilai sebesar 6,91 persen berdasarkan data Publikasi Statistik yang dirilis oleh Badan Pusat Statistik (BPS) per Maret tahun 2019.

Persentase yang cukup tinggi untuk penduduk miskin di Provinsi Jawa Barat diduga disebabkan oleh beberapa faktor, diantaranya yaitu faktor pengaruh wilayah ataupun faktor-faktor penduga lainnya. Faktor-faktor penduga tersebut perlu diketahui agar pemerintah dapat membuat suatu kebijakan publik yang tepat untuk mengurangi tingkat kemiskinan yang terjadi di Provinsi Jawa Barat. Provinsi Jawa Barat terdiri dari 18 kabupaten dan 9 kota yang saling berdekatan dan memiliki kemiripan karakteristik antar wilayahnya. Oleh karena itu wilayah kabupaten/kota di Jawa Barat diduga memiliki keterkaitan secara spasial.

Faktor-faktor yang diduga berpengaruh secara signifikan terhadap persentase penduduk miskin di Jawa Barat dapat diketahui berdasarkan suatu metode tertentu. Salah satu metode yang bisa digunakan untuk menganalisis data yang melibatkan kabupaten/kota dan dalam periode waktu tertentu dengan efek spasial di dalamnya adalah metode analisis regresi spasial data panel. Regresi spasial data panel digunakan untuk menganalisis data yang mengandung unsur spasial dan melibatkan gabungan antara data lintas individu dengan data lintas waktu. Regresi spasial data panel penting digunakan pada jenis data gabungan antara lintas individu dan lintas waktu yang memiliki efek spasial karena apabila analisis hanya menggunakan analisis regresi klasik maka analisis akan mengindikasikan ketidakakuratan (Anselin, 2009).

\section{METODOLOGI}

\section{Bahan dan Data}

Data yang digunakan dalam penelitian ini merupakan data sekunder yang diperoleh dari website resmi Badan Pusat Statistik (BPS) Provinsi Jawa Barat dan juga website resmi Jabar Open Data. Data yang digunakan merupakan data yang berkaitan dengan kemiskinan dan meliputi unit amatan sebanyak 18 Kabupaten dan 9 kota di Provinsi Jawa Barat dimulai dari tahun 2015 hingga tahun 2019. Variabel-variabel yang digunakan pada penelitian ini ditunjukkan pada TABEL 1.

TABEL 1. Variabel Penelitian

\begin{tabular}{cl}
\hline Variabel & \multicolumn{1}{c}{ Keterangan } \\
\hline Y & Persentase Penduduk Miskin \\
UHH $\left(\mathrm{X}_{1}\right)$ & Usia Harapan Hidup \\
JP $\left(\mathrm{X}_{2}\right)$ & Jumlah Penduduk \\
APS $\left(\mathrm{X}_{3}\right)$ & Angka Partisipasi Sekolah usia 16-18 tahun \\
PPK $\left(\mathrm{X}_{4}\right)$ & Pengeluaran per Kapita Disesuaikan \\
RLS $\left(\mathrm{X}_{5}\right)$ & Rata-rata Lama Sekolah \\
\hline
\end{tabular}




\section{Metode Penelitian}

Tahapan-tahapan yang perlu dilakukan dalam menganalisis data kemiskinan di Provinsi Jawa Barat menggunakan metode regresi spasial data panel adalah sebagai berikut:

1. Melakukan eksplorasi data dengan analisis deskriptif untuk melihat karakteristik data secara umum.

2. Melakukan analisis regresi data panel

a. Mengestimasi parameter model data panel, yaitu model gabungan atau Common Effect Model (CEM), model pengaruh tetap atau Fixed Effect Model (FEM), dan model pengaruh acak atau Random Effect Model (REM).

b. Melakukan uji Chow untuk memilih model antara model gabungan (CEM) atau model pengaruh tetap (FEM), dengan $\mathrm{H}_{0}: \alpha_{1}=\alpha_{2}=\cdots=\alpha_{n}=0$ dan $\mathrm{H}_{1}$ : minimal ada satu $\alpha_{i} \neq 0 ; i=1,2, \ldots, n$ (Baltagi, 2005). Apabila hasil menunjukkan $\mathrm{H}_{0}$ tidak ditolak, maka model yang terpilih yaitu Common Effect Model, tetapi apabila hasil menunjukkan penolakan terhadap $\mathrm{H}_{0}$, maka model yang terpilih yaitu Fixed Effect Model.

c. Melakukan uji Hausman untuk memilih model antara model pengaruh tetap (FEM) yang mengasumsikan bahwa nilai intersep berbeda antar individu dan nilai slope selalu sama dengan model pengaruh acak (REM) yang mengasumsikan bahwa nilai intersep berbeda baik antar individu ataupun waktu dan nilai slope selalu konstan dan perbedaan antar individu dan periode waktu diakomodasi melalui error (Nachrowi and Usman, 2006). Hipotesis dari uji ini yaitu $\mathrm{H}_{0}$ : korelasi $\left(x_{i t}, \varepsilon_{i t}\right)=0$ dan $\mathrm{H}_{1}$ : korelasi $\left(x_{i t}, \varepsilon_{i t}\right) \neq 0$ (Baltagi, 2005). Apabila hasil menujukan $\mathrm{H}_{0}$ tidak ditolak, maka model yang terpilih yaitu Random Effect Model dan apabila hasil menunjukkan penolakan terhadap $\mathrm{H}_{0}$, maka model yang terpilih yaitu Fixed Effect Model.

3. Melakukan analisis regresi spasial data panel

a. Menentukan matriks pembobot spasial. Pada penelitian ini matriks pembobot spasial menggunakan pendekatan matriks Queen Contiguity karena matriks ini memiliki prinsip bahwa pembentukan matriks disusun berdasarkan persinggungan sisi dan sudut. Matriks juga perlu dinormalisasi baris dengan tujuan agar jumlah dari masing-masing baris menjadi sama dengan satu (Dubin, 2009).

b. Melakukan uji Moran's I untuk melihat kebergantungan spasial antar wilayahnya (Lee and Wong, 2001).

c. Melakukan uji Pengganda Lagrange atau biasa disebut Lagrange Multiplier Test untuk menguji interaksi spasial pada suatu model. Apakah model memiliki interaksi spasial pada lag atau interaksi spasial pada error (Anselin, 1988).

d. Melakukan pendugaan parameter Fixed Effect Spatial Error Model (SEM) (Elhorst, 2014).

e. Melakukan uji signifikansi yang terdiri dari uji Likelihood Ratio (Elhorst, 2014) dan uji signifikansi parameter (uji T) (Alvitiani, Yasin and Mukid, 2019).

f. Menguji asumsi yang harus dipenuhi, diantaranya yaitu uji normalitas, uji homoskedastisitas, uji autokorelasi, dan uji multikolinearitas.

4. Menginterpretasikan model yang terbentuk dari Fixed Effect Spatial Error Model (FE SEM). 


\section{HASIL DAN PEMBAHASAN}

\section{Eksplorasi Data}

Eksplorasi data pada penelitian ini menggunakan analisis deskriptif yang bertujuan untuk melihat gambaran karakteristik data secara umum. Hasil analisis deskriptif dari masing-masing variabel yang digunakan dalam penelitian disajikan pada tabel di bawah.

TABEL 2. Statistik Deskriptif

\begin{tabular}{llll}
\hline \multicolumn{1}{c}{ Variabel } & Minimum & Maksimum & Rata-rata \\
\hline Persentase Penduduk Miskin (\%) & 2.07 & 16.28 & 8.806 \\
Usia Harapan Hidup (Tahun) & 68.36 & 75.89 & 71.74 \\
Jumlah Penduduk (Jumlah) & 181.425 & 5.965 .410 & 1.778 .721 \\
APS Usia 16-18 Tahun (\%) & 46.19 & 86.3 & 68.88 \\
Pengeluaran per Kapita Disesuaikan (Ribu Rupiah) & 6.875 & 17.254 & 10.246 \\
Rata-rata Lama Sekolah (Tahun) & 5.46 & 11.1 & 8.22 \\
\hline
\end{tabular}

Statistik deskriptif selanjutnya ditampilkan dalam bentuk peta persebaran persentase penduduk miskin di Provinsi Jawa Barat.

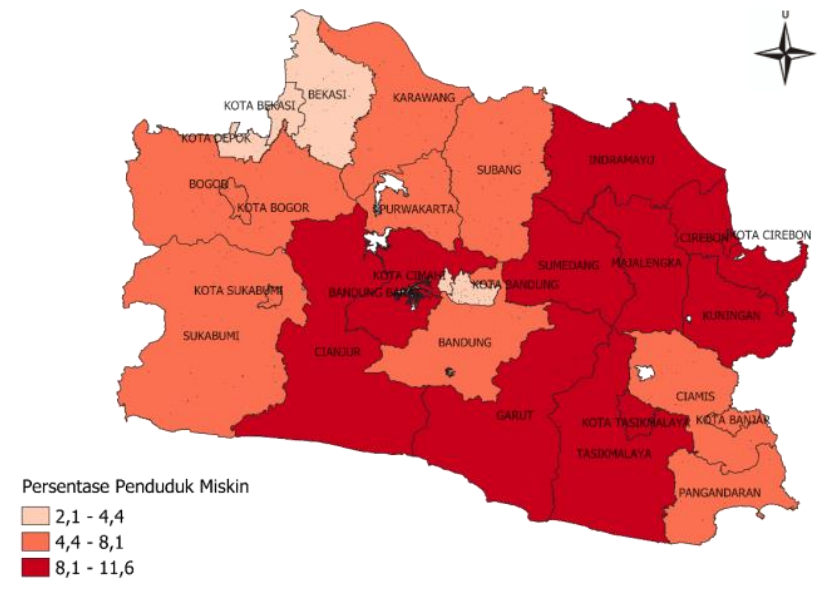

GAMBAR 1. Peta Persebaran Persentase Penduduk Miskin di Jawa Barat Tahun 2019

Kategori yang terbentuk dari peta persebaran persentase penduduk miskin di Provinsi Jawa Barat yaitu kategori rendah yang dimulai dari angka $2.1 \%$ - 4.4\%, kategori sedang yang dimulai dari $4.4 \%$ $8.1 \%$, dan kategori tinggi yang dimulai dari angka $8.1 \%$ - 11.6\%. Peta persebaran persentase penduduk miskin di Provinsi Jawa Barat terlihat membentuk pola spasial, hal ini terbukti dengan tingkat kemiskinan yang cenderung mirip untuk setiap wilayah yang saling berdekatan.

\section{Estimasi Parameter Regresi Data Panel}

Setelah melakukan eksplorasi data, langkah selanjutnya yaitu mengestimasi parameter dan membentuk ketiga model regresi data panel yaitu model Common Effect, model Fixed Effect, dan model Random Effect.

\section{Common Effect Model}

$$
\mathrm{Y}=1,8111+3,1015 \times 10^{-1} \mathrm{UHH}-5,7658 \times 10^{-8} \mathrm{IP}+1,7563 \times 10^{-2} \mathrm{APS}-5,7139 \times 10^{-4} \text { PPK-1,1664RLS }
$$


2. Fixed Effect Model

$$
\mathrm{Y}=\alpha_{\mathrm{L}}-1,1824 U \mathrm{HH}+2,0142 \mathrm{x} 10^{-1} \text { IP }-1,3046 \mathrm{x} 10^{-2} \text { APS }-1,3480 \mathrm{x} 10^{-9} \text { PPK }-9,1850 \mathrm{x} 10^{-1} \text { RLS }
$$

\section{Random Effect Model}

$$
\mathrm{Y}=6,1467 \times 10^{1}-4,7323 \times 10^{-1} \text { UHH }-1,2299 \times 10^{-\pi} \text { IP }-1,5732 \times 10^{-2} \text { APS }-1,4481 \times 10^{-1} \text { PPK }-3,1283 \times 10^{-1} \text { RLS }
$$

$$
\text { Uji Chow }
$$

Uji ini berfungsi untuk memilih model antara model Common Effect dengan model Fixed Effect. Hasil dari uji Chow ditampilkan pada tabel di bawah,

TABEL 3. Hasil Uji Chow

\begin{tabular}{cc}
\hline F Statistic & p-value \\
\hline 81.436 & $2,2 \times 10^{-16}$ \\
\hline
\end{tabular}

berdasarkan TABEL 3, perolehan nilai-p dari uji Chow < 0.05 yang berarti model Fixed Effect terpilih sebagai model yang digunakan.

\section{Uji Hausman}

Uji ini berfungsi untuk memilih model antara model Random Effect dengan model Fixed Effect. Hasil dari uji Hausman ditampilkan pada tabel di bawah ini,

TABEL 4. Hasil Uji Hausman

\begin{tabular}{cc}
\hline Chisq Statistic & Nilai-p \\
\hline 4.9199 & 0.02655 \\
\hline
\end{tabular}

berdasarkan TABEL 4, perolehan nilai-p dari uji Hausman $<0.05$ yang berarti model Fixed Effect terpilih sebagai model yang digunakan.

Setelah dilakukan uji Chow dan uji Hausman, diperoleh hasil bahwa model Fixed Effect terpilih sebagai model yang sesuai pada analisis ini. Sebelum melanjutkan tahap selanjutnya, pada pendugaan Fixed Effect Model terdapat variabel yang tidak signifikan yaitu variabel Angka Partisipasi Sekolah Usia 16-18 Tahun $\left(\mathrm{X}_{3}\right)$ yang memperoleh nilai-p sebesar 0.245505. Sehingga diperlukan pendugaan parameter model Fixed Effect dengan mengeluarkan variabel $\mathrm{X}_{3}$ sebagai model yang tidak signifikan.

Variabel $\mathrm{X}_{3}$ dikeluarkan dari model didukung dengan hasil tes diagnostik dari uji normalitas yang memperoleh nilai-p sebesar 0.01318 , yang berarti residual tidak berdistribusi normal dan hasil dari uji homoskedastisitas yang menunjukkan bahwa nilai-p sebesar 0.0416, yang berarti terjadi heterokedastisitas pada model. Model Fixed Effect yang terbentuk tanpa variabel $\mathrm{X}_{3}$ adalah sebagai berikut.

$$
\mathrm{Y}=\alpha_{\mathrm{L}}-1,1791 \mathrm{UHH}+2,1532 \times 10^{-6} \text { IP }-1,3708 \times 10^{-9} P P K-9,5623 \times 10^{-1} \text { RLS }
$$

\section{Matriks Pembobot Spasial}

Langkah pertama dari pembuatan matriks pembobot adalah mengisi seluruh elemen matriks dengan angka 1 jika wilayah saling bersinggungan baik secara sisi maupun sudut dan angka 0 untuk wilayah yang tidak bersinggungan. Setelah itu matriks dilakukan normalisasi. Normalisasi pada umumnya menggunakan normalisasi baris yang berarti matriks pembobot ditransformasi sehingga menghasilkan sama dengan satu dari setiap masing-masing baris (Dubin, 2009). Matriks pembobot spasial yang digunakan berukuran $27 \times 27$ sesuai dengan banyaknya jumlah kabupaten/kota di Provinsi Jawa Barat. 
Uji Moran's I

Untuk mengetahui apakah terdapat autokorelasi spasial atau disebut juga dengan ketergantungan spasial antar lokasi perlu dilakukan uji Moran's I. TABEL 5 adalah nilai-nilai p dari hasil uji Moran's I.

TABEL 5. Nilai-p Hasil Uji Moran's I

\begin{tabular}{ccccccc}
\hline \multirow{2}{*}{ Tahun } & \multicolumn{5}{c}{ Variabel } \\
\cline { 2 - 7 } & $\mathrm{Y}$ & $\mathrm{X}_{1}$ & $\mathrm{X}_{2}$ & $\mathrm{X}_{3}$ & $\mathrm{X}_{4}$ & $\mathrm{X}_{5}$ \\
\hline 2015 & $6,946 \times 10^{-8}$ & $1,268 \times 10^{-6}$ & $6,511 \times 10^{-5}$ & $4,331 \times 10^{-6}$ & $5,875 \times 10^{-6}$ & $6,655 \times 10^{-7}$ \\
\hline 2016 & $1,74 \times 10^{-7}$ & $1,621 \times 10^{-6}$ & $5,157 \times 10^{-5}$ & $4,497 \times 10^{-5}$ & $6,469 \times 10^{-6}$ & $6,574 \times 10^{-7}$ \\
\hline 2017 & $1,301 \times 10^{-7}$ & $2,182 \times 10^{-6}$ & $4,094 \times 10^{-5}$ & 0.0001471 & $5,115 \times 10^{-6}$ & $1,636 \times 10^{-6}$ \\
\hline 2018 & $4,812 \times 10^{-8}$ & $3,069 \times 10^{-6}$ & $3,258 \times 10^{-5}$ & 0.0006678 & $7,566 \times 10^{-6}$ & $1,129 \times 10^{-6}$ \\
\hline 2019 & $4,369 \times 10^{-8}$ & $3,792 \times 10^{-6}$ & $2,605 \times 10^{-5}$ & 0.0006472 & $9,941 \times 10^{-6}$ & $5,185 \times 10^{-7}$ \\
\hline
\end{tabular}

Berdasarkan TABEL 5, nilai-p yang diperoleh dari masing-masing variabel $<0.05$. Hal ini menunjukkan bahwa terdapat autokorelasi spasial pada variabel dependen maupun independen.

Uji Pengganda Langrange (LM)

Uji ini memiliki fungsi untuk menguji interaksi spasial pada data panel, yaitu uji pengaruh pada lag spasial (SAR) dengan $\mathrm{H}_{0}: \delta=0$ dan $\mathrm{H}_{1}: \delta \neq 0$, juga uji pengaruh pada error spasial (SEM) dengan $\mathrm{H}_{0}: \rho=0$ dan $\mathrm{H}_{1}: \rho \neq 0$ (Anselin, 1988).

TABEL 6. Hasil Uji Pengganda Lagrange

\begin{tabular}{ccc}
\hline Uji Lagrange Multiplier & Nilai LM & Nilai-p \\
\hline LM SAR & 3,7703 & 0.05217 \\
LM SEM & 12,89 & 0.0003303 \\
\hline
\end{tabular}

TABEL 6 menunjukkan hasil dari analisis uji Lagrange Multiplier untuk lag model dan juga error model. Untuk model SAR, nilai-p menunjukkan hasil sebesar $0.05217>0.05$ yang berarti tidak terdapat ketergantungan lag spasial pada model. Sedangkan nilai-p untuk model SEM menunjukkan hasil sebesar $0.0003303<0.05$ yang berarti terdapat ketergantungan error spasial pada model.

\section{Estimasi Parameter Fixed Effect Spatial Error Model}

Berdasarkan analisis yang sudah dilakukan sebelumnya, model yang diduga parameternya merupakan model panel Fixed Effect dan model spasial yang digunakan adalah model Spatial Error. Hasil pendugaan parameter model Fixed Effect Spatial Error Model disajikan pada TABEL 7.

TABEL 7. Hasil Estimasi Parameter Fixed Effect Spatial Error Model

\begin{tabular}{ccc}
\hline Peubah & Koefisien & Nilai-p \\
\hline$\rho$ & 0.463215 & $1,308 \times 10^{-6}$ \\
$\mathrm{X}_{1}$ & -0.52040 & 0.0006706 \\
$\mathrm{X}_{2}$ & 0.16655 & 0.5688316 \\
$\mathrm{X}_{4}$ & -0.81296 & $2,549 \times 10^{-9}$ \\
$\mathrm{X}_{5}$ & -0.62722 & $1,982 \times 10^{-5}$ \\
\hline \multicolumn{3}{c}{ R-square $=0.982$} \\
\hline
\end{tabular}


Estimasi parameter model Fixed Effect Spatial Error dari TABEL 7 menghasilkan model sebagai berikut.

$$
\begin{gathered}
y_{i t}=-0,52040 U_{H} H_{i t}+0,16655 J P_{i t}-0,81296 P P K_{i t}-0,62722 R L S_{i t}+\mu_{i}+u_{i t} \\
u_{i t}=0,463215 \sum_{j=1}^{27} W_{i j} u_{i t}+\varepsilon_{i t}
\end{gathered}
$$

\section{Uji Signifikansi}

Uji Likelihood Ratio

Uji Likelihood Ratio memiliki tujuan untuk melihat apakah terdapat pengaruh yang signifikan antara variabel independen dengan variabel dependen secara bersamaan dalam model Fixed Effect Spatial Error Model sehingga model dapat digunakan atau tidak.

TABEL 8. Hasil Uji Likelihood Ratio

\begin{tabular}{cc}
\hline Nilai Likelihood Ratio & $\boldsymbol{p}$-value \\
\hline 35.282 & $4,066 \times 10^{-7}$ \\
\hline
\end{tabular}

Nilai-p yang diperoleh dari uji Likelihood Ratio adalah sebesar 4,066 x $10^{-7}<0.05$ yang berarti terdapat pengaruh yang signifikan antara variabel independen dengan variabel dependen secara bersamaan dalam model Fixed Effect Spatial Error Model sehingga model dapat digunakan.

\section{Uji Signifikansi Parameter (Uji T)}

Uji T berfungsi untuk memeriksa apakah terdapat pengaruh yang signifikan dari masing-masing variabel independen terhadap variabel dependen.

TABEL 9. Hasil Uji T

\begin{tabular}{ccccc}
\hline Peubah & Koefisien & Nilai-t & Nilai-p & Keterangan \\
\hline$\rho$ & 0.45189 & 4.6486 & $3,342 \times 10^{-6}$ & Signifikan \\
$\mathrm{X}_{1}$ & -0.518535 & -3.3868 & 0.0007072 & Signifikan \\
$\mathrm{X}_{2}$ & 0.164382 & 0.5596 & 0.5757741 & Tidak Signifikan \\
$\mathrm{X}_{3}$ & -0.016087 & -0.06158 & 0.5380555 & Tidak Signifikan \\
$\mathrm{X}_{4}$ & -0.812089 & -5.9547 & $2,606 \times 10^{-9}$ & Signifikan \\
$\mathrm{X}_{5}$ & -0.620135 & -4.2182 & $2,463 \times 10^{-5}$ & Signifikan \\
\hline
\end{tabular}

Berdasarkan TABEL 9, ada beberapa variabel independen yang berpengaruh secara signifikan terhadap variabel dependen, diantaranya yaitu variabel Usia Harapan Hidup $\left(\mathrm{X}_{1}\right)$, Pendapatan per Kapita Disesuaikan $\left(\mathrm{X}_{4}\right)$, serta Rata-rata Lama Sekolah $\left(\mathrm{X}_{5}\right)$. Hal ini menunjukkan bahwa variabelvariabel tersebut berpengaruh secara signifikan terhadap persentase penduduk miskin di Provinsi Jawa Barat.

\section{Uji Asumsi}

Berdasarkan hasil output dari software RStudio, nilai-p dari uji asumsi normalitas adalah sebesar 0.1157 yang menandakan bahwa residual berdistribusi normal karena nilai-p > 0.05. Selanjutnya dilakukan uji asumsi homoskedastisitas dan memperoleh nilai-p sebesar 0.2171 yang menandakan tidak terjadi kasus heterokedastisitas pada model Fixed Effect Spatial Error. Asumsi yang harus 
dipenuhi selanjutnya yaitu asumsi autokorelasi dengan perolehan nilai Durbin-Watson sebesar $2.209076>$ nilai $d_{U}$ yaitu 1.7527 yang berarti tidak terdapat autokorelasi antar residual. Asumsi terakhir yang perlu dipenuhi yaitu asumsi multikolinearitas yang memperoleh nilai VIF untuk masingmasing variabel yanitu variabel $\mathrm{X}_{1}$ (3.055388), $\mathrm{X}_{2}$ (3.055388), $\mathrm{X}_{4}$ (3.055388), dan $\mathrm{X}_{5}$ (3.055388), dimana seluruh variabel memiliki nilai $\mathrm{VIF}<10$, yang berarti tidak terjadi multikolinearitas pada variabel independen.

\section{Interpretasi Model Fixed Effect Spatial Error Model}

Model Fixed Effect Spatial Error memiliki nilai koefisien determinasi ( $R$-square) sebesar 0.982 atau $98,2 \%$. Hal ini menunjukkan bahwa persentase penduduk miskin di Provinsi Jawa Barat pada tahun 2015-2019 dapat dijelaskan oleh faktor-faktor yang terdapat pada model sebesar 98,2\%, sedangkan sisanya $1,8 \%$ dijelaskan oleh faktor lain di luar model.

Pada model dijelaskan bahwa turunnya Persentase Penduduk Miskin sebesar $0.52040 \%$ dikarenakan meningkatnya 1 tahun Usia Harapan Hidup. Peningkatan Pengeluaran per Kapita Disesuaikan sebesar Rp 100.000,00 akan membuat Persentase Penduduk Miskin menurun sebesar $0.81296 \%$. Meningkatnya 1 tahun Rata-rata Lama Sekolah akan membuat Persentase Penduduk Miskin menurun sebesar 0.62722\%. Sedangkan Jumlah Penduduk tidak memiliki pengaruh yang signifikan terhadap Persentase Penduduk Miskin. Nilai interaksi error spasial adalah sebesar 0.463215 memiliki arti bahwa persentase penduduk miskin dari setiap kabupaten/kota akan dipengaruhi oleh besarnya persentase penduduk miskin kabupaten/kota yang menjadi tetangga sebesar 0.463215 .

\section{KESIMPULAN DAN SARAN}

Berdasarkan analisis dan hasil yang sudah dibahas sebelumnya, model yang terbentuk dari analisis data kemiskinan Provinsi Jawa Barat menggunakan metode regresi spasial data panel adalah Fixed Effect Spatial Error Model. Model ini terpilih menjadi model terbaik dengan perolehan nilai $R$-square sebesar 0.982. Hasil analisis juga menunjukkan bahwa terdapat beberapa faktor yang berpengaruh secara signifikan terhadap persentase penduduk miskin di Provinsi Jawa Barat, diantaranya yaitu usia harapan hidup, pengeluaran per kapita disesuaikan, dan rata-rata lama sekolah. Sedangkan faktor jumlah penduduk tidak memiliki pengaruh yang signifikan terhadap persentase penduduk miskin di Provinsi Jawa Barat.

Saran yang dapat diberikan yaitu pada penelitian selanjutnya matriks pembobot yang digunakan bisa menggunakan matriks pembobot lainnya, karena pada penelitian ini matriks pembobot yang digunakan yaitu matriks pembobot Queen Contiguity. Penelitian juga bisa dilanjutkan dengan pendugaan parameter dan pembentukan model menggunakan Spatial Durbin Model karena terdapat autokorelasi spasial antar wilayah pada variabel dependen dan independennya. Penambahan variabel yang diduga berpengaruh signifikan terhadap persentase penduduk miskin di Provinsi Jawa Barat juga dapat dilakukan pada penelitian selanjutnya.

\section{REFERENSI}

Alvitiani, S., Yasin, H. and Mukid, M. A. (2019) 'Pemodelan Data Kemiskinan Provinsi Jawa Tengah Menggunakan Fixed Effect Spatial Durbin Model', Jurnal Gaussian, 8(2), pp. 220-232. doi: 10.14710/j.gauss.v8i2.26667.

Anselin, L. (1988) Spatial Econometrics: Methods and Models. Netherlands: Kluwer Academic Publishers.

Anselin, L. (2009) 'Spatial Regression', in Fotheringham, A. and Rogerson, P. (eds) Handbook of Spatial Analysis. London : Sage Publications.

Baltagi, B. H. (2005) Economic Analysis of Panel Data. 3rd edn. John Wiley \& Sons, Ltd. 
Dubin, R. (2009) 'Spatial Weights', in Fotheringham, A. and Rogerson, P. (eds) Handbook of Spatial Analysis. London: Sage Publications.

Elhorst, J. P. (2014) Spatial Econometrics From Cross-Sectional Data to Spatial Panels. Springer Heidelberg New York Dordrecht London. doi: 10.1007/978-3-642-40340-8.

Lee, J. and Wong, D. W. . (2001) Statistical Analysis with Arcview GIS. New York: John Wiley \& Sons.

Nachrowi, D. N. and Usman, H. (2006) 'Pendekatan Populer dan Praktis Ekonometrika untuk Analisis Ekonomi dan Keuangan', Jakarta: Lembaga Penerbit FE UI. 